PONTIFÍCIA UNIVERSIDADE CATÓLICA DO RIO DE JANEIRO

\title{
Participação feminina no mercado de esportes
} eletrônicos

\section{Rafael Moutinho Lanna}

Trabalho de Conclusão de Curso

Centro de CIÊNCIAS SOCIAIS - CCS

DEPARTAMENTO de ADMINISTRAÇÃO

Graduação em Administração de Empresas 
Rio de Janeiro, Junho de 2019.

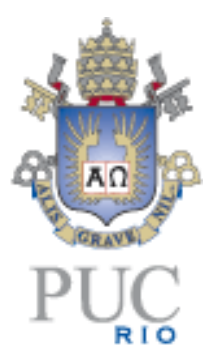

Rafael Moutinho Lanna

Participação feminina no mercado de esportes eletrônicos

Trabalho de Conclusão de Curso

Trabalho de Conclusão de Curso, apresentado ao programa de graduação em Administração da PUC-Rio como requisito parcial para a obtenção do título de graduação em Administração.

Orientador(a): Daniel Kamlot

Rio de Janeiro, Junho de 2019. 
"Uma crença não é apenas uma idéia que a mente possui, é uma idéia que possui a mente." - Robert Oxton Bolt 


\section{Agradecimentos}

Gostaria de agradecer primeiramente aos meus pais e familiares por terem me dado a oportunidade de estudar na PUC-Rio, uma das melhores faculdades do Brasil. Aos meus amigos e namorada por compartilharem diversos momentos importantes durante essa trajetória.

Ao meu orientador, Daniel Kamlot, por me ajudar nesta etapa tão importante. A todos os professores que contribuíram com minha formação, as experiência e momentos compartilhados me tornaram uma pessoa melhor e com mais conhecimento. Obrigado. 


\title{
Resumo
}

O mercado de esportes eletrônicos no Brasil e no mundo possui predominantemente homens como representantes. O objetivo desta pesquisa é entender o comportamento da consumidora feminina e suas motivações, mostrando o grande espaço que elas podem ocupar com relação a esse mercado. Os conceitos utilizados abordam temas como o processo decisório dos consumidores, suas motivações e a modalidade de E-Sports. Foi realizada uma pesquisa exploratória através da seleção de sujeitos com experiência neste mercado para responderem um questionário, e os dados foram analisados e interpretados pelo autor. O trabalho propõe mudanças na atual conjuntura do mercado de E-Sports para uma maior inclusão de mulheres, bem como ações que possam incentiva-las a dar continuidade a suas vidas profissionais no setor.

Palavras-chaves: Motivação, Mulheres, E-Sports

\begin{abstract}
The electronic sports market in Brazil and in the world has predominantly men as representatives. The objective of this research is to understand the behavior of female consumers and their motivations, showing the great space that they can have on this market. The concepts used address issues such as consumer decision-making, motivation and ESports. An exploratory research was performed through the selection of subjects with experience in this market to answer a questionnaire, and the data were analyzed and interpreted by the author. The paper proposes changes in the current environment of the ESports market for greater inclusion of women, as well as actions that may encourage them to continue their professional lives in the sector.
\end{abstract}

Keywords: Motivation, Women, E-Sports 


\section{Sumário}

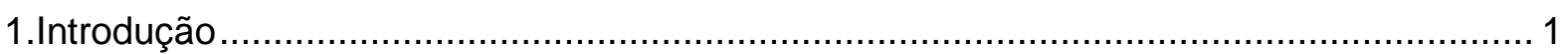

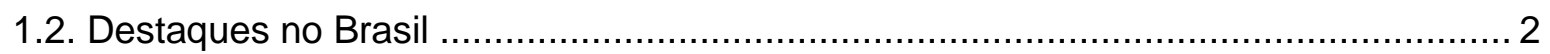

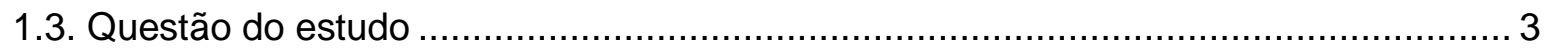

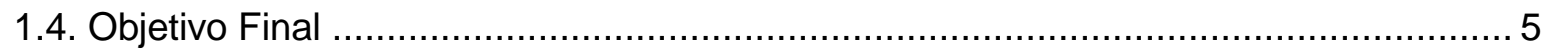

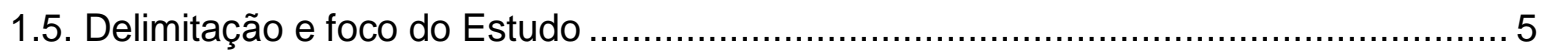

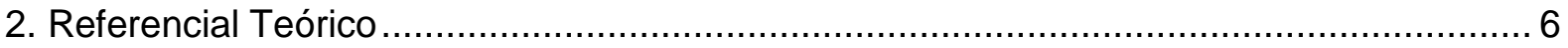

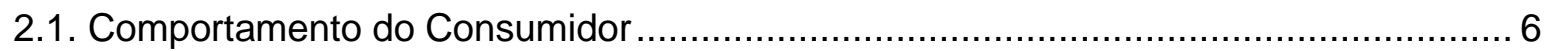

2.1.1. Processo de Decisão dos Consumidores ............................................................ 7

2.1.2. Classificação de Clientes ................................................................................ 7

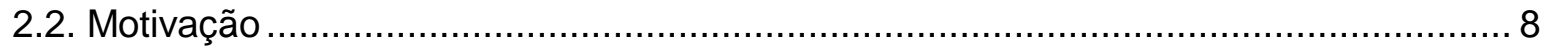

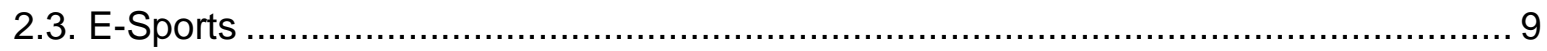

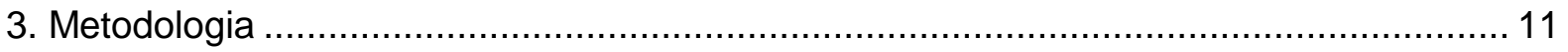

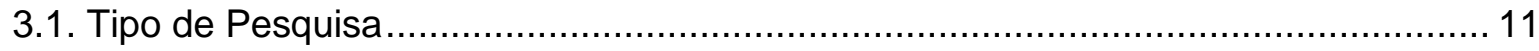

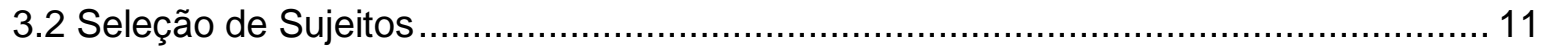

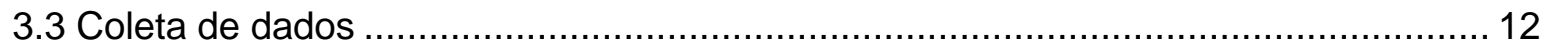

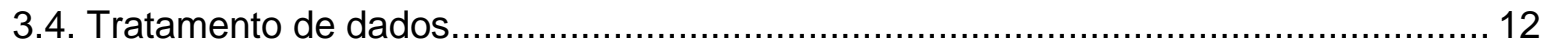

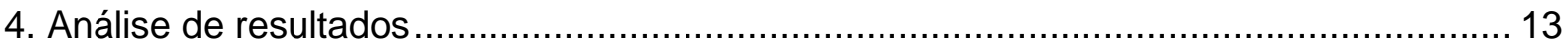

5. Conclusões e recomendações para novos estudos .................................................. 17

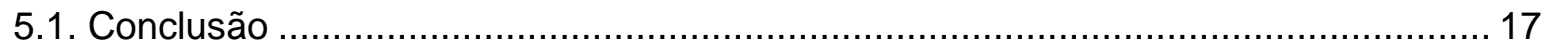

5.2. Sugestões e recomendações para novos estudos........................................... 18

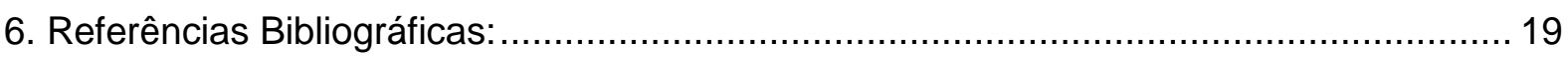

\section{Lista de Figuras}

Figura 1 - Receita do E-Sports em 2016 no mundo por região.......................................... 1

Figura 2 - Representatividade do consumidor de esporte eletrônico no Brasil ...................... 4

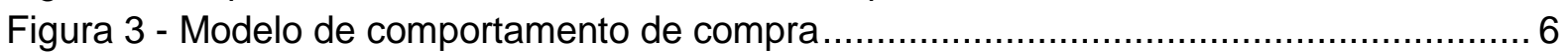

Figura 4 - Pirâmide da hierarquia de valores de Maslow e exemplos .................................... 9

\section{Lista de Tabelas}

Tabela 1 - Perfil das Respondentes do Questionário

\section{Lista de Gráficos}

Gráfico 1 - Previsão do aumento de cada fonte de receita do E-Sports em 2019. 


\section{Introdução}

\subsection{Contexto do esporte eletrônico no mundo}

Há alguns anos, era difícil pensar que um dia alguém poderia trabalhar "jogando videogame". Mas, com a facilidade de transmissão de informações hoje em dia através da internet, o chamado esporte eletrônico (comumente conhecido como E-Sports) tornou-se um fenômeno no mercado, que vem crescendo exponencialmente, movimentando no ano de 2016 mais de 700 milhões de dólares como visto na Figura 1 e com audiência em média de 400 milhões de espectadores (SuperData, 2016).

Figura 1 - Receita do E-Sports em 2016 no mundo por região

\section{Receitas mundiais dos e-Sports por região, 2016RE}

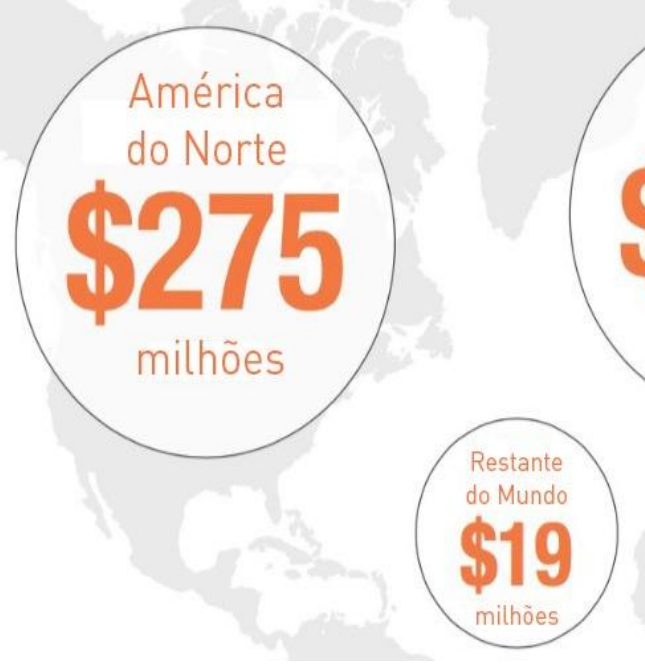

Fonte: Traduzido de SuperData research, 2016

Inicialmente criados para entretenimento, os E-Sports acabaram se tornando fonte de renda para muitos jovens ao redor do mundo. Por causa da grande popularidade, os usuários passaram a se interessar não só pelo jogo como hobby, mas também pelos jogadores mais bem-sucedidos de cada área, que se tornaram uma espécie de celebridades na internet.

Nasce uma nova profissão, os jogadores profissionais dos diversos jogos, online e 
offline, e, logo em seguida, também nascem algumas outras, como produtores de conteúdo e influenciadores digitais, ainda que em um universo de nicho. Como consequência, pela grande quantidade de público, atraem marcas e o ambiente da publicidade, gerando grandes remunerações, além de patrocínios de todo tipo de marca, como por exemplo a Coca-Cola, o McDonald's, a Nike, o Submarino, entre outras gigantes conhecidas.

\subsection{Destaques no Brasil}

Apesar de não ser um mercado ainda muito conhecido, os jogos eletrônicos vêm conquistando seu espaço, com a presença consolidada de jogadores e times profissionais, torcida, competições em estádios de futebol lotados, prêmios com remuneração milionária, campeonatos com narradores e transmissões em tempo real (por meio da internet ou até mesmo em canais especializados em esportes, como atualmente no Brasil no SporTV e similares) além dos patrocínios de grandes marcas já citados.

A partir do final de 2017, grandes times de futebol no Brasil também viram potencial nesse mercado e abriram espaço para o esporte eletrônico, iniciando uma onda de grandes investimentos e compras de times já existentes no $E=S p o r t s$, como o clube do Santos que comprou a Dexterity, e tudo isso devido ao grande público apaixonado, como qualquer torcedor brasileiro de esportes. Também há fatos curiosos de figuras famosas como Ronaldo Fenômeno que comprou metade de um dos times mais tradicionais do país, a CNB. Esses fatos somados aos patrocínios só mostram a importante parcela de mercado que eles representam, sendo a parte mais rentável do negócio. Conforme visto no Gráfico 1, a previsão das fontes de receita do E-Sports em 2019 será de um grande aumento principalmente com patrocínios e direitos de mídia, e haverá uma pequena queda apenas na taxa para produtora de games, que tende a diminuir com a tendência de lançamento de jogos gratuitos. 
Gráfico 1 - Previsão do aumento de cada fonte de receita do E-Sports em 2019

\section{FONTES DE RECEITA DO E-SPORT 2019 / GLOBAL}

INCLUINDO CRESCIMENTO ANO A ANO

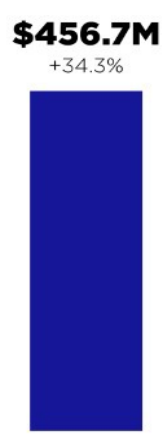

PATROCÍNIO
$\$ 251.3 M$

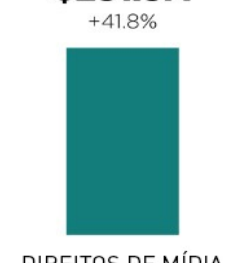

DIREITOS DE MÍDIA

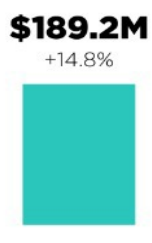

PROPAGANDA
$\$ 1.1 \mathrm{~B}$

Receita total do e-sport 2019. $+26.7 \%$ ano a ano.

Fonte: Traduzido de NewZoo, 2018

Com números impressionantes de crescimento e uma expectativa de dobrar esses valores até 2020 , possuindo uma indústria já sólida de games com um público fanático e se espelhando nos esportes tradicionais como forma de monetização (torneios em estádios, venda de ingressos e itens dos games, grandes patrocínios e ampla publicidade) o E-Sports é a grande promessa para o futuro em termos de investimento lucrativo segundo a empresa de consultoria NewZoo, 2017.

\subsection{Questão do estudo}

Mesmo com todas essas características positivas que envolvem o mercado dos esportes eletrônicos, ainda há relevantes questões a serem respondidas, e uma delas é a participação do público feminino nessa nova modalidade. Com participação de apenas $4 \%$ do público total conforme a figura 2, as mulheres ainda têm bastante espaço a conquistar nesse mercado. Qual motivação que levaria essas mulheres a praticarem mais o E-Sports e darem continuidade a essa carreira? 
Figura 2 - Representatividade do consumidor de esporte eletrônico no Brasil

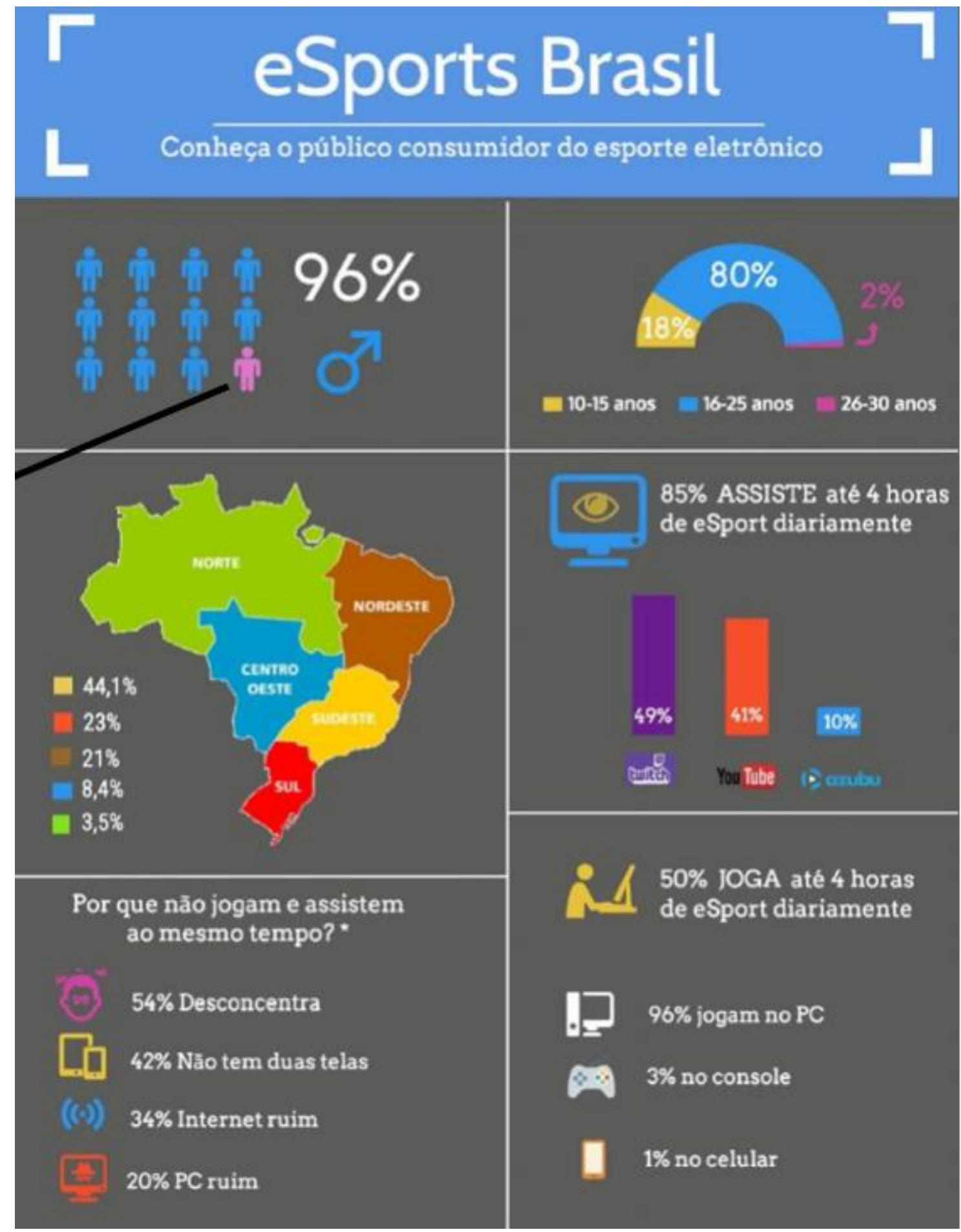

Fonte: Traduzido de NewZoo, 2017 


\subsection{Objetivo Final}

Este trabalho tem como objetivo analisar o comportamento das consumidoras brasileiras do E-sports e o motivo delas representarem uma parcela tão pequena do público geral, identificando as principais características do objeto de estudo - mulheres praticantes do esporte eletrônico, buscando possíveis motivações que as levam a praticá-lo e avaliando dados relevantes sobre a inclusão de mulheres neste mercado.

\subsection{Delimitação e foco do Estudo}

O estudo contempla mulheres na faixa etária de dezesseis a trinta anos, idade que representa $80 \%$ do público feminino de E-Sports, na região Sudeste, que é o mercado predominante no Brasil (NewZoo, 2017), focando principalmente na cidade do Rio de Janeiro. O E-Sport avaliado neste estudo será o League of Legends e a análise terá foco em marketing.

\subsection{Relevância do Estudo}

A relevância deste estudo será o entendimento das causas da discrepância entre a participação feminina e masculina nos E-Sports, bem como a motivação de mulheres que praticam o esporte eletrônico, possibilitando empreendedores, empresas relacionadas ao esporte eletrônico e até mesmo clubes a investirem de forma inteligente nesse grande mercado com muito a ser explorado. 


\section{Referencial Teórico}

\subsection{Comportamento do Consumidor}

"Consumidores são pessoas que compram bens e serviços para si mesmas ou para outros, e não para revendê-los ou usá-los como insumos" (CHURCHILL e PETER, 2000, p. 146).

Os principais pilares que ajudam em uma melhor compreensão do comportamento do consumidor, como mostrados na Figura 3, são os fatores cultural, que diz respeito aos valores adquiridos pelo convívio social em determinada região e mostrar seus costumes e atitudes; social, que envolve grupos de referências para o consumidor, sendo considerados até mesmo "formadores de opinião"; pessoal, que são as características intrínsecas das pessoas, como sua ocupação, estilo de vida, personalidade, sexo, idade etc., e por fim o psicológico, que envolve a motivação, percepção, aprendizagem, crenças e atitudes, de acordo com Churchill e Peter(2005).

Figura 3 - Modelo de comportamento de compra

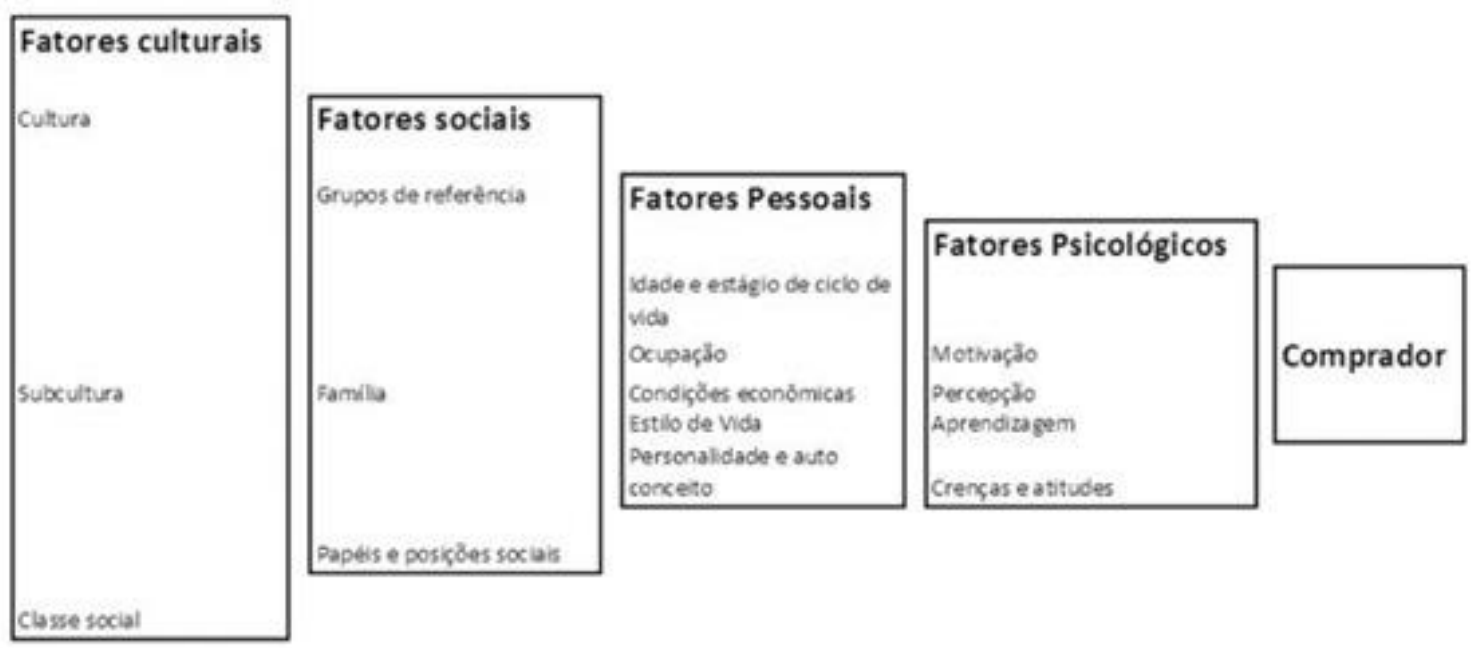

Fonte: (KOTLER; ARMSTRONG, 1995)

Fonte: (KOTLER; ARMSTRONG, 1995) 


\subsubsection{Processo de Decisão dos Consumidores}

Conforme Kotler e Keller(2006), o processo de decisão de compra dos consumidores é dividido em cinco aspectos relativos ao produto ou serviço a ser consumido: as motivações de compra de consumidores; os seus critérios de escolha entre as marcas; grau de implicação relativamente ao produto; o grau de premeditação da compra e as fontes de informação e de conselho às quais os consumidores recorrem. É muito importante analisar o grau de envolvimento dos clientes com os produtos ou serviços, o que vai impactar diretamente em sua decisão de aquisição ou não dos mesmos. São muitas as variáveis que influenciam esse comportamento, sejam elas procedentes do ambiente externo, cultura, classe social, entre outras, ou inerentes aos seres humanos, caracterizando as diferenças individuais.

O consumidor passa por cinco etapas até adquirir o produto, além da etapa final da pós compra, e são elas: o reconhecimento do problema, que é o estímulo por uma necessidade ou desejo interno ao consumidor quando ele reconhece algum tipo de problema; a busca por informações, através de fontes pessoais como família e amigos, fontes comerciais como propagandas e vendedores ou fontes públicas como a internet e as redes sociais para encontrar informações acerca do produto desejado antes de comprá-lo; a avaliação de alternativas pré compra, referente ao processamento das informações e escolha entre as possíveis opções por parte do consumidor de acordo com o que lhe convém; a decisão de compra, que envolve a tomada de decisão do consumidor, de forma planejada ou por impulso para realizar a compra e obter o produto; por fim a avaliação pós compra, que é o momento de maior conhecimento sobre o produto adquirido e as experiências positivas, podendo gerar compras semelhantes na mesma empresa ou recomendações, ou negativas, deixando-o insatisfeito, o que irá desencadear num processo de reclamações, pedidos de troca e até mesmo devoluções.

\subsubsection{Classificação de Clientes}

Segundo Sheth, Mittal e Newman(2001), existem clientes ou consumidores domésticos e clientes ou consumidores comerciais, que adquirem tanto produtos como serviços. As diferenças a serem consideradas são entre os consumidores que adquirem e utilizam os produtos e os que adquirem e consomem os serviços. Consumidores domésticos são os consumidores finais, os últimos da cadeia de comercialização, por exemplo o cliente que faz compras em um mercado. Já os clientes organizacionais, são organizações que compram produtos de outras organizações, seja para consumo em sua produção ou para revenda, 
como uma empresa de móveis que compra madeira de uma madeireira para uso em sua produção. Também há a classificação de acordo com o sexo, que varia nos diferentes tipos de segmentos de mercado. O público masculino tende a agir diferente do feminino em cada contexto, seja classe social, localização, idade, educação, tipo do mercado etc.

\subsection{Motivação}

"A motivação refere-se a um estado alterado de uma pessoa, o qual conduz a um comportamento voltado a um objetivo. Ela é constituída de várias necessidades, sentimentos e desejos que conduzem as pessoas a este comportamento. A motivação começa com a presença de um estímulo que impulsiona o reconhecimento de uma necessidade." Mowen; Minor (2005).

Uma das bases das teorias motivacionais é a Teoria de Maslow e a hierarquia de valores, que são caracterizadas em cinco níveis que mais motivam uma pessoa, sendo a base da pirâmide o mais importante e o topo dela o menos, como na Figura 4, sendo o fisiológico as necessidades básicas, a segurança a busca por garantias tanto físicas como psicológicas, o relacionamento uma necessidade de aceitação e participação, a estima o reconhecimento dentro de um grupo ou classe social e a auto realização o impulso interno de utilizar todo seu potencial através da aquisição de novos conhecimentos e satisfações. A teoria apresentou falhas pois foi percebido que o indivíduo muitas vezes inverte a pirâmide, se preocupando mais com a auto realização e a estima que com as necessidades primárias e a segurança, e isso na ótica do marketing se reflete na vontade das pessoas de adquirir um produto ou serviço de luxo sem ter condições, privando-se do básico. 
Figura 4 - Pirâmide da hierarquia de valores de Maslow e exemplos

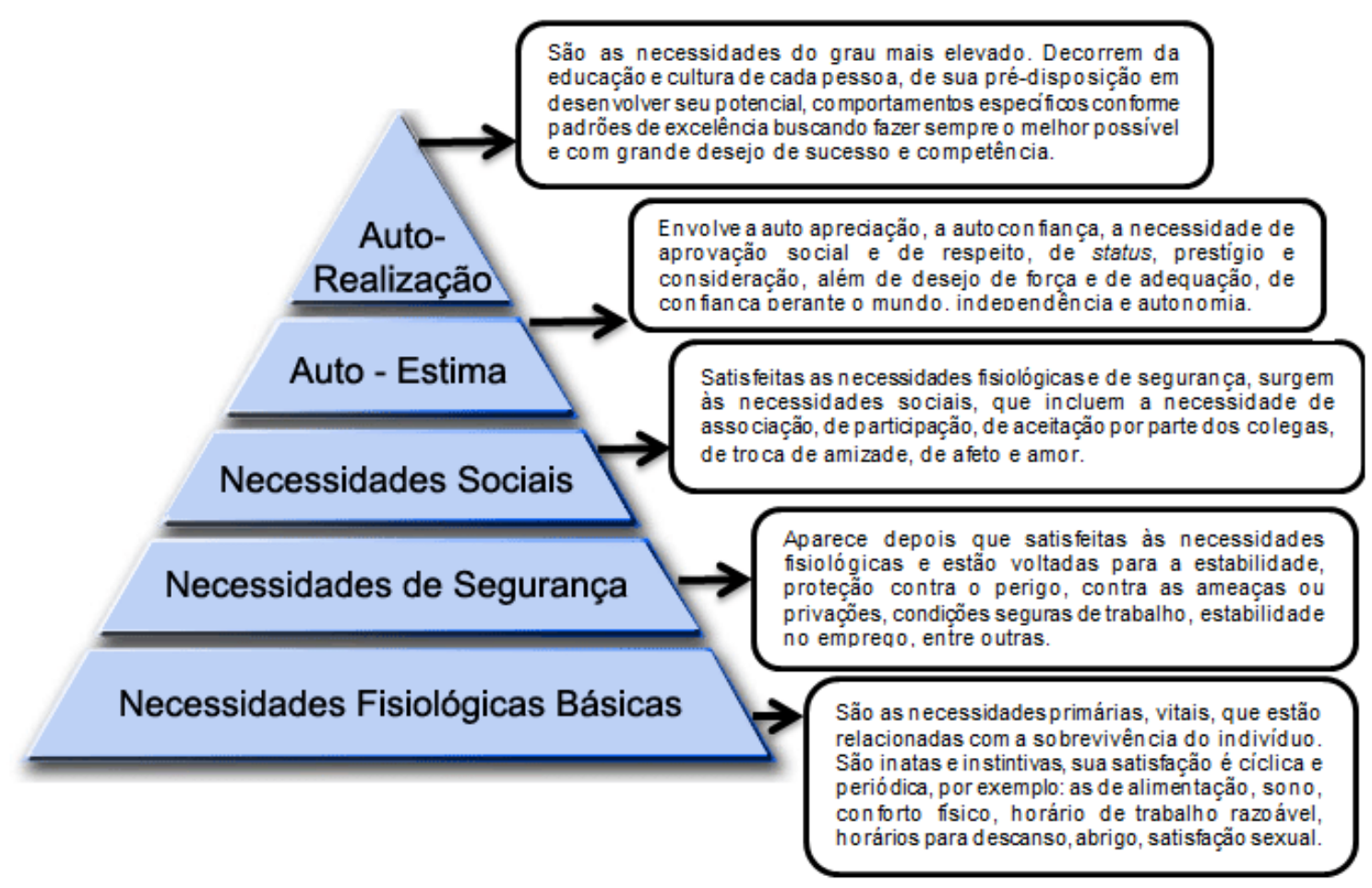

Fonte: Adaptado de (Maslow, 1970)

A motivação é percebida em diversos níveis, podendo vir através de fatores internos ou externos, sendo o primeiro uma influência de estímulos vindos do organismo humano e gerando ações impulsivas, e o segundo relativo a influências externas que uma pessoa está suscetível a receber de acordo com seu ciclo de convivência e seus hábitos, além de influências indiretas como informações que ela recebe sem perceber. Esse conceito de motivação interna no marketing é exemplificado pelo desenvolvimento de uma vontade própria de adquirir um produto a fim de satisfazer-se, ou uma busca de realização profissional, enquanto a motivação externa se origina de algo que está em evidência na sociedade, como a vontade de adquirir uma roupa que está na moda por exemplo.

\subsection{E-Sports}

De acordo com Mendes(2006), os esportes eletrônicos são modalidades de competição profissional de jogos eletrônicos. Sua concentração inicial e surgimento foi na região Asiática, mas logo se estendeu por todo o mundo. Eles estão mais associados a esportes não tradicionais como o xadrez por não possuírem uma necessidade física grande, 
mas sim uma psicológica e mental, testando também os limites de agilidade e a capacidade de raciocínio dos praticantes. No começo, o E-Sports tinha pouca audiência e representação nos meios de comunicação, principalmente pela falta de jogos online e de boas internets que permitissem melhores experiências nesses jogos. Entretanto, a partir dos anos 2000 houve um aumento significativo da popularidade deste mercado, onde ocorreu também o surgimento de jogadores e equipes profissionais, que são patrocinados por grandes marcas não só de games, mas também de outros segmentos como o de esportes e o alimentício, e participam de eventos e campeonatos ao vivo, geralmente em estádios de futebol, com premiações em dinheiro para os concorrentes.

Segundo o site Significados.com(2018), os títulos mais populares em competições profissionais são o League of Legends(comumente conhecido com LoL), DotA 2 e Counter Strike: Global Offensive. Segue uma breve explicação de cada um:

- $\quad$ "League of Legends é um jogo online competitivo que mistura a velocidade e a intensidade de um RTS ${ }^{1}$ com elementos de RPG ${ }^{2}$. Duas equipes de poderosos campeões, cada um com design e estilo único, lutam em diversos campos de batalha e modos de jogo. Com um elenco de campeões em constante expansão, atualizações frequentes e uma cena competitiva exuberante, League of Legends oferece diversão incessante para jogadores de todos os níveis de habilidade." (Fonte: League of Legends Brasil)

- $\quad$ "Counter - Strike é um modo para Half-Life onde você joga pela internet. Há dois times, os counter- terrorist (Policiais) e os Terrorists (Terroristas). Os jogadores se dividem entre os times, o objetivo dos Policiais é resgatar os reféns e eliminar os terroristas, por sua vez os terroristas não podem deixar os policiais resgatarem os reféns eliminando os policiais, vence o time que eliminar todos do outro. Um jogo que mistura estratégia e ação ." (Fonte: Sitecs)

- $\quad$ "DotA 2 é o MOBA ${ }^{3}$ da Valve, empresa dona da Steam, baseado em um antigo mod $^{4}$ de Warcraft 3, o Defense of the Ancients (DotA) no qual os jogadores devem se enfrentar online em acirradas batalhas entre equipes. Mantendo o gameplay do original, ele apresenta gráficos e efeitos sonoros melhorados." (Fonte: Techtudo)

\footnotetext{
${ }^{1}$ Real Time Strategy

2 Role-playing game

${ }^{3}$ Multiplayer Online Battle Arena

${ }^{4}$ Modificação em um jogo para operar de uma forma diferente da original
} 


\section{Metodologia}

\subsection{Tipo de Pesquisa}

Foi utilizada a pesquisa exploratória como tipo de pesquisa, visto que este é um tema ainda pouco conhecido, a partir de um questionário com respostas mais aprofundadas de pessoas que possuem ou possuíram experiências práticas relacionadas ao tema, possibilitando a construção de hipóteses plausíveis.

\subsection{Seleção de Sujeitos}

A seleção de sujeitos foi constituída por mulheres residentes do Rio de Janeiro que jogam ou jogaram o esporte eletrônico League of Legends. A tabela 1 mostra cada uma das dez respondentes e suas características.

\section{Tabela 1 - Perfil das Respondentes do Questionário}

\begin{tabular}{|c|c|c|c|}
\hline Respondente & Idade & Jogos preferidos & Experiência no mercado de E-Sports \\
\hline 1 & 24 & League of Legends e CS:GO & $\begin{array}{l}\text { Atualmente moderadora de uma das grandes páginas de facebook de } \\
\text { League of Legends, o League of Legends da Depressão. Jogou durante } 3 \\
\text { anos competitivamente }\end{array}$ \\
\hline 2 & 19 & League of Legends e CS:GO & $\begin{array}{l}\text { Participa de um time feminino de League of Legends que está tentando se } \\
\text { classificar para o Circuito Desafiante }\end{array}$ \\
\hline 3 & 22 & League of Legends & $\begin{array}{l}\text { Jogou como reserva por um dos times do Circuito Desafiante de League of } \\
\text { Legends, etapa anterior ao CBLoL(Campeonato Brasileiro de League of } \\
\text { Legends) }\end{array}$ \\
\hline 4 & 22 & Ragnarok e League of Legends & $\begin{array}{l}\text { Ex-jogadora de um time do Circuito Desafiante de League of Legends. } \\
\text { Atualmente streamer, joga casualmente }\end{array}$ \\
\hline 5 & 26 & Heroes of the Storm e League of Legends & $\begin{array}{l}\text { Tentou jogar competitivamente League of Legends por } 4 \text { anos, mas nunca } \\
\text { conseguiu um time grande para se destacar }\end{array}$ \\
\hline 6 & 28 & League of Legends e Overwatch & Participou de competições menores por influência de amigos \\
\hline 7 & 24 & Hearthstone e League of Legends & $\begin{array}{l}\text { Cobre eventos como jornalista para uma página de E-Sports e joga } \\
\text { casualmente }\end{array}$ \\
\hline 8 & 25 & World of Warcraft e League of Legends & $\begin{array}{l}\text { Participa de competições universitárias de E-Sports, representando a } \\
\text { UFMG }\end{array}$ \\
\hline 9 & 28 & League of Legends e Lunia Z & $\begin{array}{l}\text { Trabalhou } 2 \text { anos na Riot Games, empresa criadora do jogo League of } \\
\text { Legends, em uma de suas unidades em São Paulo, atuando na área da } \\
\text { produção do CBLoL(Campeonato Brasileiro de League of Legends) }\end{array}$ \\
\hline 10 & 20 & Diablo 3 e League of Legends & $\begin{array}{l}\text { Tem conhecimento de diversos jogos e acompanha o cenário competitivo } \\
\text { brasileiro de League of Legends, tentando se tornar uma jogadora } \\
\text { profissional }\end{array}$ \\
\hline
\end{tabular}

Fonte: Pesquisa de Campo(2019) 


\subsection{Coleta de dados}

A coleta de dados foi realizada com pessoas previamente selecionadas pelo pesquisador que responderam perguntas abertas (Anexo 1) feitas através dos aplicativos WhatsApp e Facebook. Tais perguntas foram desenvolvidas com o intuito de descobrir a motivação que levou as respondentes a começarem a jogar League of Legends e a participar de competições do esporte eletrônico, e entender o espaço que as mulheres possuem nesse mercado. Este método de pesquisa permite aos respondentes serem espontâneos em suas respostas. Os resultados coletados a partir das perguntas feitas no questionário foram exportados para o Planilhas Google a fim de facilitar suas interpretações e possibilitar a geração de relatórios.

\subsection{Tratamento de dados}

Para o tratamento dos dados coletados foi utilizada a abordagem qualitativa, que tem como característica a análise das percepções, intenções e comportamentos dos respondentes, e este método foi escolhido porque auxilia na compreensão das motivações e comportamento das consumidoras de E-Sports. Por meio de um questionário com perguntas abertas, foi realizada uma análise de discurso para compreendê-las e estruturar relatórios que têm como foco o ponto de vista dos respondentes sobre do tema.

\subsection{Limitações do método}

O método utilizado possui uma seleção pequena de sujeitos, podendo não ser a visão da maioria acerca do assunto. Outro limitador é a parcialidade das pessoas que responderam ao questionário por serem fãs do jogo, e a possível influência positiva ou negativa causada por esses jogos - principalmente League of Legends - na vida dessas pessoas. Além disso, embora o envio do questionário online seja muito conveniente, há o fator limitador de o pesquisador não ver o respondente, perdendo potenciais informações de acordo com seus movimentos e expressões. 


\section{Análise de resultados}

Os sujeitos analisados pelo método da pesquisa exploratória foram compostos por dez respondentes, oito entre 18 e 25 anos, e duas entre 25 e 30 anos, sendo todas do sexo feminino. Todas tiveram algum contato com o jogo League of Legends, foco do estudo, mas citaram alguns outros jogos como importantes em suas trajetórias no mercado de esportes eletrônicos, dentre esses os mais citados sendo Overwatch e CS:GO. Sobre o que levou essas mulheres a começarem a jogar jogos competitivos online, sete das respondentes citaram diversão e entretenimento como principal atrativo, e três delas foram influenciadas por amigos, familiares e namorados.

Observou-se um comportamento curioso entre as respondentes: apesar de todas jogarem os jogos online, menos da metade participou de grandes competições, mesmo tendo muito envolvimento nesse mercado. Dentre as quatro que participaram, duas citaram os incentivos de amigos novamente como motivação para sua participação nessas competições, e em relação às outras duas, uma mencionou a vontade de competir e testar suas habilidades, e a outra o interesse em participar de grandes eventos e ser reconhecida. A mesma respondente que falou sobre reconhecimento como sua principal motivação expôs também a parte que a desmotiva acerca do assunto:

"Eu gostava muito da competição em si, pessoas torcendo por mim, pelo meu time, ganhando ou perdendo a sensação de ter um trabalho reconhecido, saber que todo treino valeu a pena é muito gratificante. Há também o outro lado da moeda, eu como única mulher do time, muitas vezes sofria com atitudes infantis e machistas do público, se ganhássemos, o time tinha performado bem, mas na derrota a culpada na maioria das vezes era eu, chegavam ao ponto de falarem para eu ir lavar louça. Isso era muito desmotivante para mim, mesmo com companheiros de equipe que me apoiaram muito, preferi parar com as competições e virar streamer." (Respondente 4)

Sobre as seis que responderam não a pergunta do motivo de não participarem de competições de E-Sports, a primeira não teve a oportunidade por falta de apoio dos familiares, a segunda nunca conseguiu participar de um time para poder competir e a última tem vontade mas não tem tempo pois estuda e trabalha. As outras três participaram de competições pequenas, como campeonatos online de pequenos 
organizadores ou entre amigos, mas nunca conseguiram ou tiveram vontade de tentar entrar para os grandes torneios como o Campeonato Brasileiro de League of Legends(CBLoL). Essa base é válida para entender que a maior parte das respondentes tem interesse em participar em algum grau das grandes competições do mercado de esportes eletrônicos, mas nem todas tiveram oportunidade.

Quando questionadas sobre a participação das mulheres nas competições de ESports, a grande maioria disse ter conhecimento acerca desse número ser menor que 10\% (NewZoo, 2017). Todas citaram o machismo, em diferentes níveis, envolvido nos jogos online e no mercado de esportes eletrônicos como um todo. Uma das respondentes mencionou a objetificação das mulheres fora e dentro dos jogos: para ela, o destaque das mulheres em competições de E-Sports está diretamente relacionado com sua aparência física, ou seja, se seus padrões de beleza não forem de acordo com o gosto do público, ela não terá destaque e será motivo até mesmo de piadas, independentemente de suas habilidades dentro do jogo. A respeito da objetificação nos jogos, ela relacionou a sexualização das personagens femininas pelas empresas criadoras, que, em sua maioria, são criadas com poucas roupas e possuem grandes seios e nádegas, tudo isso para atrair mais o público masculino que tem interesse nesse aspecto. Outra respondente falou sobre a falta de incentivo e fomento nesse mercado, com pouca visibilidade para as ligas exclusivamente femininas (que praticamente não existem), desestimulando mais ainda quem quer tentar um espaço dentro do E-Sports:

"Eu como organizadora do time da UFMG e participante das ligas universitárias (uma das poucas, se me lembro de ter jogado contra mais de 3 mulheres foi muito), percebo que não há incentivo algum para nós mulheres, e deveria sim existir como forma de tentar manter uma igualdade, visto que nós sofremos muito nesse ambiente, e acredito que seja por isso que poucas mulheres realmente tentem participar de alguma competição. Eu não desisto, e luto sempre para melhorar esses números, dentro da UFMG estou sempre procurando mulheres que joguem, e sempre pedindo a meu time e amigos próximos para me ajudarem nessa iniciativa de formar times exclusivamente femininos que não sofram preconceitos." (Respondente 8)

As outras respondentes focaram mais no ambiente tóxico para elas nas partidas online onde muitas vezes quando sabem que são mulheres jogando, recebem xingamentos, piadas com conteúdo sexuais e machistas, inibindo a presença de mais mulheres no cenário, e isso só ratifica a unanimidade em relação ao machismo presente no mercado e a falta de punição para tal, sendo citado por todas as respondentes, inclusive as que não possuíam 
conhecimento dos números tão inferiores da participação das mulheres em relação aos homens.

Após isso, foi perguntado alguns exemplos de sugestões para mudar esse cenário e ampliar a participação da mulher no mercado de esportes eletrônicos, bem como sua participação nas competições de jogos online. Foram sugeridas diversas medidas como a criação e divulgação maior de mais ligas femininas, punições mais severas para aqueles que agem de forma machista através de xingamentos e expressões que inferiorizam as mulheres, campanhas de conscientização voltadas para a mudança da mentalidade dos homens que praticam esse tipo de atitude, incentivos para as mulheres através de patrocínios, representatividade e apoio entre as próprias mulheres para que possam ser vistas como capazes de pertencer a este espaço. Uma das respondentes que trabalhou na empresa criadora do League of Legends, em São Paulo, conta um pouco sobre sua experiência e seus desafios, como mulher, de participar desse mercado:

"Quando trabalhei na Riot, tive uma experiência incrível. Conheci muita gente, participei de muitos eventos e entendi melhor esse mercado fascinante que cada ano se torna mais promissor. Eu trabalhava com a produção do CBLoL, e um de nossos desafios era justamente a inclusão maior de mulheres no cenário de E-Sports brasileiro, como casters, analistas, jogadoras etc, de forma suave, para que o público fosse digerindo essa maior igualdade no mercado aos poucos. Realizamos várias ações, punimos muitos jogadores, inclusive jogadores profissionais que tiveram atitudes tóxicas durantes jogos normais em casa, contratamos profissionais super competentes como a Camilota, e isso acho que tem ajudado. Mas isso não pode vir só da Riot, nós mulheres devemos nos unir e mostrar nosso valor nesse mercado, as possibilidades são muitas." (Respondente 9)

Como citado pela própria respondente e apoiado por outras, o mercado é muito grande e promissor para as mulheres, e deve ser incentivado de todas as formas possíveis, não só pelas empresas envolvidas, mas por toda a base de jogadores que irá se beneficiar, pois com a maior participação feminina e consequentemente de jogadores no geral o investimento das empresas de jogos será maior assim como o lucro dessas empresas.

Sobre as considerações finais que pudessem contribuir com esta pesquisa, uma das respondentes falou sobre seu dia a dia cobrindo eventos de E-Sports e a importância da participação das mulheres nesses eventos: 
"Queria enfatizar que em todos os eventos que eu participo as mulheres são um público com voz muito ativa, desde as torcedoras apaixonadas até as que estão ali apenas para curtir o evento, e acho que um aumento de sua representatividade nesse mercado em geral pode trazer um aumento de audiência nos eventos de E-Sports, sendo de grande valor para as empresas que patrocinam esses eventos, para os jogadores profissionais que vão ter mais fãs e para a própria produção do evento que vai contar com mais público, por isso que é tão importante conseguirmos esse espaço, não somente aparecer em competições como jogadoras profissionais, mas como público amante dos joguinhos!" (Respondente 7) 


\section{Conclusões e recomendações para novos estudos}

\subsection{Conclusão}

Esta pesquisa pretendeu investigar a participação e o espaço que as mulheres possuem no mercado de esportes eletrônicos, e o foco do estudo recaiu sobre o comportamento das mulheres e suas motivações com relação a grande discrepância de sua participação em relação aos homens, que se mostra uma questão importante e um grande mercado potencial para se investir.

Para aprofundar essa análise, foi utilizada como base a perspectiva de Kotler e Keller(2006) quanto ao comportamento do consumidor, com foco em mulheres no nicho de jogos online, e a de Mowen; Minor(2005) sobre as motivações que satisfazem um consumidor, entendendo a motivação dessas mulheres em participar de competições no mercado de esportes eletrônicos.

Para atingir o objetivo final do estudo, foi realizada uma pesquisa exploratória com dez respondentes, todos do sexo feminino, que contribuíram com sua experiência e visão do mercado que participam.

Dentre as principais questões abordadas, concluiu-se que o espaço das mulheres no mercado de esportes eletrônicos é pequeno principalmente por uma questão cultural, o grande machismo na sociedade de hoje, além de aspectos como o foco atual das empresas de games ser voltado para o público masculino e as baixas penalidades para quem infringe regras mais graves por se tratar de jogos online(não há políticas que envolvam a pessoa física, apenas o banimento da conta do usuário, o que encoraja o público a agir sem seguir as regras). Para mudar essa situação, deve-se focar em publicidades principalmente por parte de empresas criadoras de jogos, conscientizando sua base de jogadores e aumentando a severidade das punições a quem não seguir as regras. Elas também devem reestruturar sua forma de atrair clientes, principalmente do sexo masculino, através da sexualização de personagens femininas, e encontrar maneiras de agradar aos dois públicos.

Outro ponto é a percepção de potencial por parte de investidores, clubes e empresas que o público feminino de E-Sports representa uma base com pessoas interessadas e dedicadas nesse meio que tem grandes chances de sucesso com incentivos adequados, como patrocínios, ligas especializadas e times formados apenas por mulheres. 
Por fim, a diversificação desse mercado só irá trazer benefícios, pois aumentará a base de jogadores competitivos, o que consequentemente aumentará o nível das competições, atraindo dessa forma mais espectadores e maior visibilidade para grandes patrocinadores.

\subsection{Sugestões e recomendações para novos estudos}

Como recomendações para estudos futuros acerca do tema, podem ser desenvolvidas investigações sobre o comportamento do consumidor masculino participante do mercado de esportes eletrônicos, e entender o outro lado, suas motivações e visões sobre todo processo visto neste estudo. Outra sugestão é um estudo sobre o retorno financeiro que os clubes de futebol tem em times de jogos online e a possibilidade da criação de ligas e times femininos como diversificação e atração de público. 


\section{Referências Bibliográficas:}

BRLEAGUEOFLEGENDS. Disponível em:

$<$ https://br.leagueoflegends.com/pt/game-info/get-started/what-is-lol/> Acesso em 22 abr 2019.

CHURCHILL JR., Gilbert A.; PETER, J. Paul. Marketing: criando valor para os clientes. São Paulo: Saraiva, 2000. 626 p.

KOTLER, P. KELLER, K. L. Administração de marketing. 12. Ed. São Paulo: Pearson Hall, 2006.

KOTLER, Philip.; ARMSTRONG, Gary. Princípios de marketing. Rio de Janeiro: LTC editora, 1995.

MASLOW, A. H. Motivation and Personality (2nd ed.). New York: Harper \& Row, 1970

MENDES, C. L. Jogos Eletrônicos. Diversão, Poder e Subjetivação., 1. Ed. Campinas: Papirus, 2006.

MOWEN, John C.; MINOR, Michael, 1950- Comportamento do consumidor. São Paulo: Prentice Hall, 2005.

NEWZOO. Disponível em:

< https://newzoo.com/key-numbers/> Acesso em 14 mai 2019.

RIBEIRO, Daniel. Faça download de DotA 2, um dos principais Mobas da atualidade. TECHTUDO, Brasil, 13/04/2016 Disponível em:

$<$ https://www.techtudo.com.br/tudo-sobre/dota-2.html> Acesso em 22 abr 2019.

ROBBINS, Stephen P. Comportamento Organizacional. São Paulo: Prentice Hall, 2002.

SHETH, MITTAL, NEWMAN, J. B. B. Comportamento do cliente: Indo além do comportamento do consumidor. 1. Ed. São Paulo: Atlas, 2001.

SITECS. Disponível em:

<https://www.sitecs.net/tutoriais/counterstrike.htm> Acesso em 22 abr 2019. 
SUPERDATARESEARCH. Disponível em:

<https://www.superdataresearch.com/> Acesso em 27 abr 2019. 


\section{Anexo 1:}

Roteiro do questionário utilizado na pesquisa exploratória:

1. Idade

2. Quais jogos online você mais joga/jogou?

3. O que te levou a jogar esses jogos?

4. Já participou de alguma competição de esporte eletrônico?

5. Se sim, o que te levou a participar? Se não, por quê?

6. O que te motivaria a participar dessas competições?

7. Você sabia que mulheres possuem menos de $10 \%$ de participação nessas competições?

8. Quais os motivos você acha que mais contribuem para esse número?

9. Qual sua sugestão para mudar isso e ampliar a participação das mulheres nesse mercado? 10. Se possuir alguma consideração final que não esteja nas perguntas e possa contribuir com minha pesquisa, coloque neste espaço: 